\title{
Blood pressure and sodium balance in hypertensive patients in hospital
}

\author{
P. W. DE LEEUW \\ M.D.
}

\author{
W. H. BIRKENHÄGER \\ M.D.
}

Department of Internal Medicine, Zuiderziekenhuis, Rotterdam, The Netherlands

\begin{abstract}
Summary
Ninety-one subjects with uncomplicated essential hypertension were admitted to hospital. They received a diet with a fixed amount of sodium (55 mmol/day), without calorie restriction.

Blood pressure was measured at 2-hr intervals and averaged for each day. In patients who apparently adhered to a low salt diet before admission (group I), BP dropped $5 \mathrm{mmHg}$ during the first $24 \mathrm{hr}$ and then remained stable. In patients who previously ingested more salt (group II) a similar drop in pressure occurred during the first day, but pressure declined another $6 \mathrm{mmHg}$ during the second day, to stabilize thereafter.
\end{abstract}

Both neurovegetative and sodium-dependent factors appear to contribute to the decrease in BP while the patient is in hospital.

\section{Introduction}

The mechanisms involved in the pathogenesis of essential hypertension continue to be elusive (Editorial, 1979). One way of improving our understanding could be to study the background of regressions in blood pressure (BP).

According to common clinical experience, BP tends to fall in many hypertensives as soon as they have entered hospital. This reduction is usually interpreted in terms of mental relaxation or dietary sodium restriction or both. There is no evidence, however, to support such statements. If it is true, as suggested by several epidemiological studies (Dahl, 1961; Isaacson, Modlin and Jackson, 1963; Prior et al., 1968; Freis, 1976), that the BP level is linked to the amount of sodium ingested, one would anticipate the hypotensive response of being in hospital to be related to the change in dietary sodium intake in this period. This hypothesis was tested in the present study.

\section{Patients and methods}

Ninety-one subjects (58 men, 33 women) with uncomplicated essential hypertension were admitted to hospital. Mean age was 43 (range 18-68) years in the men and 46 (range 21-70) years in the womern The diagnosis of essential hypertension was based on routine exclusion of known causes of high BPS All patients had normal values for creatinines clearance $(\geqslant 100 \mathrm{ml} / \mathrm{min})$ and none had associate cardiovascular or metabolic disease. At least weeks before admission, antihypertensive treatment was withdrawn. No patient had received diuretics in the 12 months preceding the study. Salt intake before admission varied over a wide range, althougle the majority of patients appeared to comply witio the routine advice to restrict salt as much as possible. The recommendation to restrict dietary salt intake in these patients was given irrespective of the lepeb of BP. It is the authors' practice to estimate sodifine excretion in out-patients, but they refrained from incorporating these data here because of un reliability of such urine collections.

Subjects were admitted to a metabolic wark where sodium intake was maintained at $55 \mathrm{mmol}$ day. Calorie intake was not restricted. Twenty-fouro hr urine collections for determination of sodium, potassium and creatinine were started on admission and continued for one week. Creatinine excretion: was taken as an index of complete collection $\frac{0}{3}$ Patients were up and about during the day-timeBlood pressure was recorded in the supine position $a \underline{B}$. 2-hr intervals from 8 a.m. to 12 p.m. The diastolic BP was taken at the 5th phase of the Korotkoff sounds. Mean arterial pressure (MAP) was $\mathrm{cal}_{\delta}$ culated as diastolic plus one-third of the pulse pressure and averaged for each day. For statisticat analysis Student's $t$-test was applied where ap propriate. Otherwise Wilcoxon's Rank Sum tesf was used. Results are expressed as mean \pm s.e.mean

\section{Results (Fig. 1)}

All subjects were in sodium equilibrium withitr 5 days. According to the patterns of cumulative sodium balance, 2 patient groups could be discernedis Group I consisted of 58 patients in whom there was either net sodium gain (23 patients) or no change in cumulative sodium balance ( 35 patients) befored 
urinary sodium excretion matched the new intake. Group II comprised the remaining 33 patients who apparently had a higher sodium intake before admission. All patients in group II lost sodium (on average $125 \pm 5 \mathrm{mmol}$ ) before attaining the new balance state. Sodium output on the first day of admission was $56 \pm 2 \mathrm{mmol} / 24 \mathrm{hr}$ (range 5-96 $\mathrm{mmol} / 24 \mathrm{hr}$ ) in group I, and $134 \pm 5 \mathrm{mmol} / 24 \mathrm{hr}$ (range 102-210 mmol/24 hr) in group II $(P<0.001)$. While in the following days this remained virtually unchanged in group I, it fell to $54 \pm 3 \mathrm{mmol} / 24 \mathrm{hr}$ in group II (Fig. 1). On admission, BP was similar in both groups (MAP $131 \pm 2 \mathrm{mmHg}$ in group I v. $130 \pm 3 \mathrm{mmHg}$ in group II). During the first $24 \mathrm{hr}$ in hospital, BP fell by $5 \mathrm{mmHg}$ in both groups.
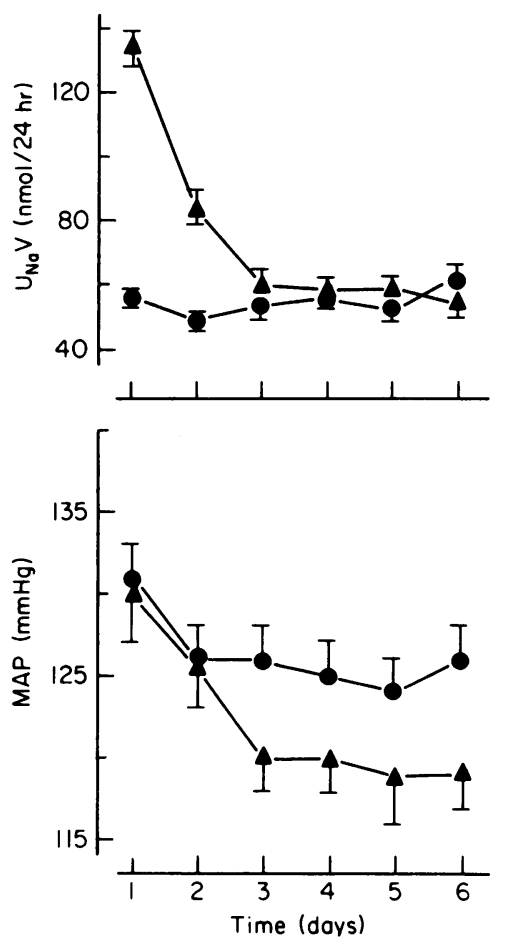

FIG 1. Patterns of urinary sodium excretion $\left(U_{\mathrm{Na}} \mathrm{V}\right)$ and mean arterial pressure (MAP), following admission to hospital, in patients from group I $(\bullet)$ and group II $(\boldsymbol{\Delta})$.

Thereafter a further pressure drop was noticed in group II, but not in group I (Fig. 1). By the time BP had stabilized it was $126 \pm 2 \mathrm{mmHg}$ in group I and $119 \pm 2 \mathrm{mmHg}$ in group II $(P<0.05)$.

\section{Discussion}

In this study, the authors attempted to define the contribution of sodium loss to the hypotensive effect of being in hospital. Some doubts could be raised as to the validity of the method of assessing sodium balance. It could be argued, for instance, that the quantity of sodium excreted during the first day of observation will be less than the daily amount of sodium ingested in the preceding period. However, the renal adaptation to a sudden change in sodium intake usually takes longer than one day (Epstein and Hollenberg, 1976). In the present study, MAP was shown to decrease by an average of $5 \mathrm{mmHg}$ during the first $24 \mathrm{hr}$ after admission. This effect occurred independently of changes in sodium balance and presumably reflects a reduction in neurovegetative pressor activity. A further pressure drop was noticed only in the patients in whom there was net sodium loss after admission (group II). It seems, therefore, that a reduction in body sodium contributed to the fall in BP in this group.

A relationship between salt consumption and the incidence of hypertension is suggested by several epidemiological studies (Dahl, 1961; Isaacson et al., 1963; Prior et al., 1968; Freis, 1976) and the beneficial effects of moderate salt restriction (Parijs et al., 1973; Morgan et al., 1978; Brummelen, Schalekamp and de Graeff, 1978). However, methodological problems do not allow one to draw definite conclusions from these investigations.

Epidemiological studies are hampered by the fact that rigid control of salt intake is not possible and assessing salt habits on the basis of random urinary collections or dietary questionnaires may not be conclusive. Moreover, other studies have failed to show a relationship between sodium excretion and BP (Simpson, 1979). In the present study, BP was similar in group I and II on the first hospital day and a relationship with previous salt intake became apparent only when changes in BP were related to changes in cumulative sodium balance.

Parijs et al. (1973), in a cross-over study in 14 patients with mild hypertension, obtained an average reduction in sodium excretion by approximately $50 \%$, i.e. $191 \cdot 1 \pm 61.2 \mathrm{mmol}$ to $92.8 \pm$ $41.8 \mathrm{mmol} / 24 \mathrm{hr}$. The decrease in sodium excretion varied across a very wide range; from a reduction by $280 \mathrm{mmol} / 24 \mathrm{hr}$ to practically no change. The results with respect to $\mathrm{BP}$ were also rather erratic. Home BP readings were significantly lower during sodium restriction. In the out-patient clinic, however, the difference in BP readings was not significant.

Morgan et al, (1978) studied the effect of sodium restriction in 31 mild hypertensives during an observation period of 2 years. After admission to the trial, subjects were only seen 4 times in that period. Systolic and diastolic BP during upright posture decreased by $10 \mathrm{mmHg}$; in the recumbent subjects, the decrease was $5 \mathrm{mmHg}$ both systolic and diastolic. Sodium excretion was reported as decreasing from $195 \pm 12 \mathrm{mmol}$ to $157 \mathrm{mmol} / 24 \mathrm{hr}$. However, in that study, creatinine excretion was 
not used as an index of accurate urine collection. Moreover the difference in sodium excretion (38 mmol) between the 2 periods was not based on a paired comparison and this may invalidate the results.

Brummelen et al., (1978) reported a decrease in BP of about $10 \mathrm{mmHg}$ with sodium restriction in 9 patients, but the study does not allow discrimination between the effects of sodium restriction and admission to hospital per se. Adaptation to the hospital and frequent BP readings appears to be associated with some reduction of BP. Such an effect was demonstrated in the patients from group I. In contrast to the earlier studies, the present one provides the opportunity to define the additional effect of changes in sodium balance upon BP, showing that a net loss of one gram of salt roughly equals a decrement of one $\mathrm{mmHg}$ in MAP. Within limits, this could be taken as a rule of thumb when sodium restriction is considered in treating hypertensive subjects.

After the establishment of sodium equilibrium the authors found they had 2 groups of hypertensives with different grades of severity. It is obvious that, at least in advanced hypertension, the study of the 'hospitalization effect' can provide only part of the answer as to whether a high salt intake increases BP.

\section{Acknowledgments}

Dr A. Wester, Mrs J. Vaarties-Steeman and Miss G. van
Soest were very helpful in retrieving the data presented in this study.

\section{References}

Brummelen, P. van, Schalekamp, M. \& de Graeff, JC (1978) Influence of sodium intake on hydrochlorothiazide음 induced changes in blood pressure, serum electrolytes renin and aldosterone in essential hypertension. Acto medica scandinavica, 204, 151.

DAHL, L.K. (1961) Possible role of chronic excess salt consumption in pathogenesis of essential hypertension:American Journal of Cardiology, 8, 571.

EdITORIAL (1979) Progress in essential hypertension. Lancet $\overrightarrow{\vec{\omega}}$ i, 1066.

Epstein, M. \& HollenberG, N.K. (1976) Age as a deter minant of renal sodium conservation in normal man Journal of Laboratory and Clinical Medicine, 87, 411.

FREIS, E.D. (1976) Salt, volume and the prevention of hypertension. Circulation, 53, 589.

IsAACSON, L.D., Modlin, M. \& JACKSON, W.P.U. (1963) Sodium intake and hypertension. Lancet, i, 946.

Morgan, T., Adam, W., Gillies, A., Wilson, M., Morgan G. \& Carney, S. (1978) Hypertension treated by sal restriction. Lancet, i, 227.

Paris,, L., Joossens, J.V., Linden, L. VAN DER, Verstreken,G. \& AMERY, A. (1973) Moderate sodium restriction andO diuretics in the treatment of hypertension. American Heart Journal, 85, 22.

Prior, I.A.M., Evans, J.G., Harvey, H.P.B., Davidson, F. \& LINDSEY, M. (1968) Sodium intake and blo pressure in two Polynesia populations. New Engla Journal of Medicine, 279, 515.

Simpson, F.O. (1979) Salt and hypertension: a sceptie review of the evidence. Clinical Science, 57, (Suppl. $\$$ ) $463 \mathrm{~s}$. 